\title{
Dualidades freudianas nas origens da Psicanálise
}

Freudian Dualities

in the Origins of Psychoanalysis

\author{
Janaina Namba \\ Universidade Federal de São Carlos [UFScar]
}

\section{RESUMO}

O texto propóe que as relaçóes entre psicanálise e filosofia estão postas a partir do momento em que nova ciência concebida por Freud teve de tomar distância em relação aos saberes médicos nos quais, no entanto, ela se origina. Cabe dizer que, pela natureza mesma do objeto que ela delineia em seu horizonte de conhecimento, a psicanálise não apenas recorre, desde o seu ensejo, à filosofia, mas ganha necessariamente uma dimensáo filosófica.

\section{PALAVRAS-CHAVE}

Metapsicologia; Filosofia; Neurologia; Simbolismo.

\begin{abstract}
The paper proposes that the relations between Psychoanalysis and Philosophy are a given from the moment that the new Science conceived by Freud has to separate itself, in some degree, from the medical knowledge in which it had its origins. The very nature of the object tha Psychoanalysis sets for itself not only requires some kind of recourse to philosophy as such but also gives it a philosophical dimension.
\end{abstract}

\section{KEY WORDS}

Metapyschology; Philosophy; Neurology; Simbolism. 
1.

Desde o primeiro momento em que surge no horizonte das preocupaçóes de Freud, a Metapsicologia tem, para ele, estreitas relaçôes com a Filosofia. Assim, numa carta a Fliess datada de 2 de abril de I896, lemos que

De modo geral, tenho feito bons progressos na psicologia das neuroses e tenho todos os motivos para estar satisfeito. Espero que você também queira ouvir sobre algumas questôes metapsicológicas. [...] Quando jovem, eu não conhecia nenhum outro anseio, senão o de conhecimentos filosóficos, e agora estou prestes a realizá-los, à medida que vou passando da medicina para a psicologia (Freud, 1986, p. I80).

Ao pensar numa metapsicologia, Freud se afastava da medicina, ou ainda, dos "cânones de cientificidade da ciência natural" (Birman, 1993, p. I6) e se aproximava, em seu entender, da filosofia. Esse fato, na visão de Joel Birman, permitiria afirmar uma afinidade entre a teorização psicanalítica e certa metafísica (diríamos nós: de extração pós-kantiana), por se contrapor, como esta, à ciência natural meramente experimental (ibid.).

Freud entende assim, desde o início, que utilizar "procedimentos de verificação experimental que náo se coadunam com a metodologia psicanalítica não confere cientificidade a esse tipo de investigação" (ibid., p. I5). Isso porque entre a psicanálise e os procedimentos experimentais utilizados pelas ciências naturais, tais como dissecçóes anatômicas descritivas, ou mesmo experimentos quantitativamente verificáveis, haveria uma incompatibilidade metodológica que não permitiria fundar a Psicanálise como ciência. Pois, ainda que o saber inventado por Freud situe os processos psíquicos em processos nervosos, que são, efetivamente, pressupostos em suas análises, não haveria uma correspondência exata entre as estruturas anatômicas e as estruturas psíquicas, do que se segue que os experimentos com estas não poderiam, a rigor, se basear num modelo físico, que pudesse ser aplicado nas mesmas condiçôes e oferecer uma verificação quantificável. O método psicanalítico baseia-se no tratamento analítico, e isso levaria a psicanálise a adotar outros padróes de cientificidade, ou melhor, a formular um padrão próprio.

Para tanto, é preciso pensar conceitualmente o objeto que se dá na experiência, e é isso o que leva Freud a atribuir à sua investigaçáo um viés filosófico, recorrendo à psicologia, ou, mais precisamente, ao que ele chama de metapsicologia, que é o conjunto das articulaçóes teóricas mais rigorosas do saber psicanalítico. Ou seja, a metapsicologia permite regular e definir teoricamente as experiências psicanalíticas. Cabe afirmar, portanto, com Rancière, "que a psicanálise é inventada no ponto em que a filosofia e a medicina se póem em causa reciprocamente, e o pensamento se torna uma questão de doença, e a doença, uma questão do pensamento" (Rancière, 200I, p. 26). A originalidade da Psicanálise, ancorada em uma Metapsicologia, consiste não em tomar o neurológico como substrato causal da representação, mas em parear ambas as instâncias de tal modo que cada uma delas se ponha como condição de possibilidade da outra. Isso se dá, como sugere Rancière, por intermédio de uma patologia. 
Em Concepção das afasias (I89I), Freud se opõe às teorias neurológicas da época, que defendiam uma localização anatômica cerebral para as funções mentais. Ainda que esse texto náo possa ser considerado psicanalítico, ele apresenta pela primeira vez os conceitos fundamentais de representação-coisa e representaçáo-palavra, que posteriormente seriam incorporados à teoria psicanalítica. O conceito de representação se opóe, no domínio da anatomia, ao de projeção, pois esta última envolve uma distribuição das fibras nervosas que ascendem desde a periferia do corpo (a partir dos órgáos sensoriais) até o sistema nervoso central, em particular na região cortical. A cada estaçáo nervosa, chamada de núcleo cinzento, as fibras são interrompidas, mas continuam ainda projetando a topografia periférica até seu destino final no córtex cerebral. Já pelo conceito de representação nervosa, as fibras também ascendem até as estaçôes nervosas, ou núcleos cinzentos, mas lá passam por um rearranjo neural, isto é, estabelecem novas conexôes com outras fibras nervosas que de lá ascendem, e, portanto, a cada estação nervosa, as informações conduzidas pelas fibras são ressignificadas até chegarem no córtex cerebral. Freud propóe assim que uma representação cortical dos estímulos externos atingiria os órgãos sensoriais, e não uma projeção.

Trata-se, portanto, de uma mudança de natureza funcional que altera a concepção mesma de sistema nervoso. Pois, se antes pensava-se que em cada estação nervosa poderia haver uma única interrupção da fibra e que essa fibra era a mesma ao longo de todo o trajeto, agora, com um rearranjo das fibras nervosas em cada estação, elas não são simplesmente interrompidas, mas outras fibras, que se conectam entre si, formam novos circuitos nervosos, alterando também a concepção da função própria do núcleo cinzento, na medida em que as fibras que aí chegam são interpretadas, e não mais apenas projetadas.

Detenhamo-nos por um instante nessa afirmação. De acordo om Freud, em cada um dos pontos de conexão haveria uma alteração na "significação [Bedeutung] funcional" da fibra. Os elementos tópicos, ao serem associados, ganham novo significado e forma, e são determinados por um princípio exclusivamente funcional, isto é, "os fatores tópicos são conservados apenas na medida em que concordam com as exigências da função" (Freud, 1983, p. I02). Segundo Freud, no cérebro,

Os processos fisiológicos partem de uma regiāo particular do córtex e se estendem para todo o restante deste, ou mesmo ao longo de vias particulares. Assim que entram em curso, eles deixam atrás de si, na camada cortical percorrida, uma modificação — a possibilidade de lembrança (ibid.).

Vê-se assim que a anatomia cede lugar à fisiologia, o modelo puramente mecanicista é flexibilizado e adquire uma dinâmica mais complexa. O substrato nervoso vivo já é em si um processo fisiológico e não difere, portanto, das funçôes mentais. É o que se vê em particular, na linguagem, que, para Freud, está intrinsecamente ligada, por um lado, ao funcionamento psíquico, ao mesmo tempo em que, por outro, é uma função de estruturas anatômicas determinadas, governadas por processos fisiológicos específicos. Como afirma Freud, "os processos fisiológicos não são interrompidos onde começam 
os processos psíquicos" (ibid., p. I05), estes últimos não são localizáveis, como ditava neurologia da época, mas estão encadeados entre si e dependem de processos fisiológicos. Ou seja, a linguagem enquanto processo psíquico, se dá em função da conexão entre as representações, que não são outra coisa que um arranjo dos componentes visuais, táteis, auditivos, cinéticos ou cinestésicos, e não necessariamente têm uma correspondência exata com o substrato neural. O estudo da afasia, tomada como patologia, oferece uma oportunidade perfeita para que Freud comece a mostrar mais diretamente aquilo que a Metapsicologia irá explorar mais a fundo, a saber, a combinação entre os elementos teóricos e empíricos da Psicanálise como ciência.

Como vimos, a ativação do córtex cerebral, decorrente de uma excitação nervosa, seria ela própria responsável pela modificação do tecido cortical, funcionaria como uma impressão, uma marca no tecido que registraria uma possível memória. Memória essa que não se encontra, portanto, circunscrita em células nervosas. Esses estímulos nervosos provenientes tanto do interior quanto do exterior do corpo estariam inscritos como traço, como representaçáo. Como explica Luiz Roberto Monzani, as representaçóes são imagos, mas que "não possuem mais o valor representativo conferido pelo pensamento clássico, subsistem em função do que são e do lugar em que estão [...], elas não reenviam mais a nada a não ser a si mesmas e à cena de que fazem parte" (Monzani, 2005, p. I29). Ao que poderíamos acrescentar, com Birman, que é a partir da radicalização de algumas teorias fisiológicas do final do século XIx (notadamente as de Jackson e Wernicke) que o discurso freudiano se apropria de "fragmentos de outros saberes então emergentes como a etnologia, arqueologia e a mitologia, [...] que colocavam Freud diante da demanda crucial de representar teoricamente essa nova forma de saber" (Birman, 1993, p. 15).

\section{2.}

No Projeto para uma Psicologia Científica (I895), obra inacabada e publicada apenas postumamente, Freud anuncia, logo na introdução, o propósito de alçar a psicologia à condição de ciência natural, apesar de certas dificuldades metodológicas. O objetivo é mostrar que os processos psíquicos podem ser tomados como "estados quantitativamente comandados por partes materiais comprováveis [...]” (Freud, 2004a, p. 339). Seria essa obra uma demonstraçáo dessa própria radicalidade de Freud, ao querer comprovar os processos que anunciara na Concepção das Afasias nos mesmos termos que a neurologia de sua época? Ou seria mais uma hesitação, ao apresentar a psicanálise ainda incipiente como uma ciência de gênero distinto das ciências naturais?

Como vimos, foi a partir da neurologia que Freud propôs uma mudança quanto ao funcionamento de algumas estruturas nervosas (núcleos cinzentos), e somente a partir dessa mudança conceitual foi possível formular a noção de representação, como preferível à de projeção. Ora, parece justificada certa hesitação quanto à formulação de uma obra que Freud náo publicou, apesar de aparentemente terem sido as próprias incompatibi- 
lidades teóricas que envolviam uma concepção quantitativa da vivência dolorosa que o tenham levado a uma reformulação do Projeto (Gabbi Jr., I99I, p. I70). No entanto, vemos, por um lado que juntamente com o conceito de representação, a utilização do sonho "como objeto de investigaçáo" (ibid.) será decisiva para uma verdadeira ruptura do discurso freudiano com as neurociências do século XIX, e por outro, uma aproximação do saber filosófico, movimento no qual se constituirá, posteriormente, a psicanálise como saber de novo tipo. Vejamos entáo, como se desenvolve a teoria freudiana da representação para a interpretação, conceito e ferramenta fundamental da psicanálise.

Como afirma Valerie Greenberg, "ao negar a teoria da projeção nervosa, Freud oferece um termo próprio, representação. E são as próprias evidências anatômicas que mostram que a imagem da periferia deve ser reconstituída" (Greenberg, 1997, p. II9).

Pode-se dizer ainda que a representação é ela própria uma interpretação, pois reconstitui o caminho feito pela impressão sensorial desde a periferia até o córtex cerebral, como uma interpretação feita pelo sonhador ao ser impelido pelo desejo de dormir no momento em que sonha. Nas palavras de Freud,

O desejo de dormir explica de maneira retorcida e caprichosa como se interpreta o estímulo externo. A interpretação correta da qual a alma dormente é perfeitamente capaz, reclamaria um interesse ativo e exigiria o cancelamento do sono; por isso, de todas as interpretações possíveis, só são admitidas aquelas compatíveis com a censura que o desejo de dormir exerce de maneira absolutista (Freud, 2004b, p. 246).

Em outras palavras, o desejo de dormir mantém afastados, na medida do possível, os estímulos externos que possam despertar quem dorme. Mas esse afastamento não é possível, quando se trata de estímulos internos, que adentram o psiquismo. Para que o sono não seja perturbado e interrompido, o indivíduo sonha, e os estímulos movimentam as representaçóes existentes no aparelho psíquico de tal modo que são interpretados em conformidade com o desejo de permanecer dormindo.

A Interpretação dos Sonhos (1900) é a obra que inaugura e define o campo psicanalítico de maneira mais sistemática, justamente por estabelecer o sonho como um fenômeno psíquico dotado de sentido. Para Freud,

Interpretar um sonho significa indicar um sentido, substituí-lo por algo que se insere na cadeia de nossos atos anímicos [...]. As teorias científicas sobre os sonhos, não deixam nenhum espaço para um eventual problema de interpretação, posto que para elas, o sonho não é absolutamente um ato anímico, mas um processo somático que se anuncia mediante certos signos no aparelho psíquico. Muito diferente foi a opiniáo do senso comum em todos os tempos. Essa opinião se serviu de seu direito para proceder de maneira inconsequente, e, ainda que admitisse que os sonhos fossem incompreensíveis e absurdos, não negavam-lhes completamente o significado. Guiada por um obscuro pressentimento, parece ela supor 
que o sonho tem um sentido ainda que oculto; estaria destinado a ser o substituto de um outro processo de pensamento e não faria mais que desvelar de maneira certeira esse sentido para alcançar o significado oculto do sonho (ibid., p. II8).

Ao romper com a neurociência vigente, Freud também rompe com muitas das teorias científicas sobre o sonho; e, além de se voltar para a filosofia, retoma tradiçóes populares, que atribuíam ao sonho alguma espécie de significado. Da mesma maneira que a opiniáo comum, a psicanálise supóe nos sonhos um conteúdo que se encontra velado, latente, e outro, que se apresenta ao sonhador, e é dito manifesto. Se, para Freud, o sonho é passível de interpretaçáo, é porque sua aparente ausência de significado indica que o psiquismo não se encontra restrito à consciência. Há uma produção inconsciente de pensamento que permanece latente e encontra-se encoberto por um material manifesto que pode surgir para a consciência. $\mathrm{O}$ trabalho de interpretaçáo seria então desvelar o sentido encoberto pelas imagens que se apresentam no sonho. Desse modo, para a psicanálise, "a suposição da existência do psiquismo inconsciente permite circunscrever uma nova concepção do psíquico", um psíquico dotado de sentido, cujo método de abordagem seria o da interpretação, na medida em que se também observava no sintoma que algo não era representado na consciência e deveria ser interpretado, isto é, ter um sentido resgatado.

Contudo, diferentemente da tradição popular, cujo método de interpretação dos sonhos é simbólica (no sentido mais lato da palavra), isto é, utiliza-se de uma chave fixa de interpretação e busca um sentido totalizante para o sonho, a psicanálise se aproxima de um método de deciframento, que se baseia num inventário preestabelecido para os signos, de modo a demarcar um universo fechado para as significaçóes. Rigorosamente, portanto, trata-se de recuperar o sentido imanente do sonho a partir da cifra que ele mesmo oferece, e não, como se costumava fazer, impor ao sonho um código alheio a ele, como se o sonhar apontasse para alguma coisa fora do próprio aparelho psíquico. Pode-se dizer que, em certa medida, o sonho é para Freud a mitologia do inconsciente: o repertório variado e colorido da expressão reiterada de uma mesma estrutura. ${ }^{\mathrm{I}}$

Segundo Freud, "o primeiro passo para a aplicação desse procedimento ensina que não se deve tomar como objeto todo o sonho, mas fragmentos singulares de seu conteúdo" (Freud, 2004b, p. I25). Isso se deve ao fato de que o sonho está relacionado à história singular de cada pessoa, náo pode se referir a um catálogo preestabelecido de signos que se correspondem entre si independentemente daquele que sonha. Assim como na clínica, cada interpretação deve levar em conta "um extenso informe prévio e uma incursão na natureza e as condiçôes etiológicas das psiconeuroses" (ibid., p. I26). Ou seja, o método de interpretação freudiano dos sonhos se baseia numa metapsicologia, que "indica uma pretensão teórica de uma pesquisa que quer ir além de uma psicologia", ou seja, "ir para além da consciência e da psicologia do comportamento, em direção à psicologia das profundidades, como Bleuler denominava a psicanálise” (Birman, 1993, p. I8). Nas próprias palavras de Freud, em nota preliminar à primeira edição da Interpretação,

I Caberia assim recuperar, a propósito da Interpretação dos sonhos, o sentido do simbólico tal como pensado por Schelling. Ver Rubens Rodrigues Torres Filho, "O simbólico em Schelling" (2006). 
O sonho é o primeiro termo na série de produtos psíquicos anormais; outros de seus termos são as fobias histéricas, as representaçôes obsessivas e as delirantes, das quais o médico deve se ocupar por razóes práticas. Como veremos, o sonho não pode exigir essa mesma importância prática; todavia, tanto maior é seu valor teórico como paradigma (Freud, 2004b, p. 17).

Ou seja, o sonho, enquanto produto psíquico, não é diferente de outras formações psíquicas anormais, pois não há diferença qualitativa entre o que é normal e o que é patológico, mas apenas quantitativa. Isso permite tratar o sonho como um modelo para a explicação dos sintomas, uma vez que ele mesmo é um paradigma teórico do aparelho psíquico, como se vê no capítulo vir da Interpretaçâo. Nesse capítulo, Freud mostra o funcionamento psíquico, a partir de um sonho paradigmático e (O menino em chamas) retoma, por esse exemplo, o que havia dito no início do capítulo III: "(O sonho) é um fenômeno psíquico de pleno direito, mais precisamente o cumprimento de um desejo, e, deve ser classificado dentro da concatenação das açóes anímicas de vigília que nos são compreensíveis" (ibid., p. I42).

Vimos, por um lado, que o sonho é um fenômeno psíquico que deve se encontrar concatenado com os outros fenômenos psíquicos, mas ele é também o cumprimento de um desejo (o desejo do pai, de que o menino estivesse vivo). Segundo Octave Mannoni, essa afirmaçáo indica uma "intencionalidade inconsciente, decorrente do fato que o motor da máquina toda é o desejo” (Mannoni, 1994, p. 74). É o que Freud diz explicitamente, no mesmo capítulo vir: "somente um desejo, nenhuma outra coisa é capaz de colocar em movimento o aparelho psíquico" (Freud, 2004b, p. 588). Na teoria dos sonhos, existe mais de um sistema, Consciente/Pré-Consciente e Inconsciente, e há dois processos que se encontram no funcionamento desses sistemas, o secundário e o primário, sendo que "sobretudo o processo primário" encontra-se a serviço do desejo inconsciente (Mannoni, I994, p. 86). Ou ainda, nos termos do capítulo viI:

A imagem mnêmica de uma certa percepção se conserva associada ao traço mnêmico da excitação resultante da necessidade. Logo que essa necessidade aparece novamente, produzir-se-á, graças à ligação que foi estabelecida, uma moção psíquica que procurará reinvestir a imagem mnêmica dessa percepção, isto é, restabelecer a situação primeira de satisfação: a essa moção chamaremos desejo; o reaparecimento da percepção é a realização do desejo (Freud apud Monzani, 2005, p. I28).

Em outras palavras, o suprimento de uma necessidade (vivência de satisfação), como, por exemplo, da fome, estabelece um circuito de memória que passa a ser investido psiquicamente, isto é, paralelamente ao circuito da necessidade se desenvolve um circuito pulsional. Nas palavras de Monzani, "é a partir do campo pulsional que se monta o circuito do desejo" (Monzani, 2005, p. I25). Esse circuito se estabelece desde o campo biológico, mas dele se desprende pelo prazer obtido dessa vivência de satisfação. $\mathrm{O}$ ato de sugar o dedo não tem nenhuma finalidade biológica, e, o prazer dele obtido se desenvolve a partir de outra que a sensaçáo momentânea de aplacar a fome decorrente do próprio 
ato de sugar. Como se vê nesse exemplo, o prazer não se põe no domínio da estrita funcionalidade biológica, proveniente de sensaçóes que emanam tanto da musculatura quanto da mucosa oral. Há um prazer que se destaca e se impóe, tendo ele próprio uma "função autônoma, como uma série paralela à série biológica" (ibid.).

A partir de pulsóes apoiadas sobre necessidades orgânicas, o prazer se desenvolve como sexualidade em condição suplementar, que acaba por se impor e modificar a própria condiçáo das necessidades orgânicas sobre as quais as pulsóes estavam apoiadas. Esse desvio, pode, por sua vez ser visto como uma ruptura, e "se, por um lado, torna possível que se escape das leis biológicas, por outro faz necessária a busca de um apoio de todas as funçôes psíquicas sobre as funçôes corporais" (Anzieu, I995, p. II9). Essa série paralela vem justamente caracterizar, do ponto de vista da psicanálise, "o que é essencial para a constituição do ser humano enquanto tal” (Monzani, 2005, p. I26). Dessa maneira, o prazer que desencadeia posteriormente o desejo que emerge do campo pulsional, diferentemente das necessidades só pode ser representado psiquicamente.

\section{3.}

Nos Três ensaios sobre a sexualidade (1905), Freud se refere à pulsão como uma "agência representante [Repräsentanz] psíquica de uma fonte de estímulos intrassomática em contínuo fluir". Isso quer dizer que o próprio corpo é uma fonte de estímulos internos que, diferentemente dos estímulos externos pontuais, agem continuamente sobre o psiquismo, onde serão representados por um agente representante. Os estímulos somáticos são interpretados pelo aparelho psíquico por meio das pulsôes, o que a torna "um conceito limite entre o anímico e o corporal” (Freud, 2004c, p. 153) e situa a Psicanálise, que as toma por objeto, em uma esfera própria, que não se confunde com a da Fisiologia nem tampouco com a da Psicologia, a meio caminho entre a mera experimentação e a especulação teórica que se opõe a ela.

Freud supóe que as pulsóes são desprovidas de qualidade e o que as distinguiria seriam suas metas e fontes, às quais estão associadas. A fonte da pulsão é um órgão ou determinada região do corpo, que a pulsão representará no aparelho psíquico e da qual podemos inferir um esforço constante, uma vez que a matéria viva encontra-se em constante atividade e assim é representada. Desta maneira, se a pulsão é representante do corpo, ela é também "uma medida da exigência de trabalho que representa" (Freud, 2004d, p. II7) ou seja, apresenta-se ao psíquico como um fator quantitativo da atividade de um órgão ou de uma região. A meta da pulsão é justamente sua própria satisfação, ela se resolve em si mesma.

Mas é importante lembrar que, além da meta e da fonte, dois outros termos estão ligados ao conceito de pulsão, a saber o objeto e o esforço. Objeto é o veículo pelo qual a pulsão alcança a satisfação. $\mathrm{O}$ objeto "não se encontra originariamente enlaçado à pulsão" e tampouco precisa ser algo diferente do próprio corpo (ibid., p. II8). Por esforço entende-se que os estímulos são constantes, assim como os estímulos fisiológicos provenientes do interior do corpo que não podem ser cancelados por meio de uma descarga 
motora. Nas palavras de Freud, a força, ou esforço "é a essência da pulsão, pois toda pulsão é um fragmento de atividade" (ibid., p. II7).

Se, no Três Ensaios, Freud apresentava a pulsão como um representante psíquico, dez anos mais tarde, em Pulsóes e seus destinos, ele diz que a pulsão não é ela a própria representação, e, no entanto, é preciso haver representação, pois a pulsão, por ter uma fonte corpórea, não pode se apresentar por si mesma no aparelho psíquico. Em seus textos metapsicológicos ( $O$ Inconsciente e Pulsóes e seus Destinos) ele passa a se referir a uma agência representante de representação da pulsão, e não mais a um representante do corpóreo no psíquico que dá conta da representação de uma determinada região corporal. A agência representante de representação da pulsão seria então "uma representação ou um grupo de representaçôes investidas por um montante de energia psíquica desde a pulsão" (id., 2004e, p. I47).

Isso explica porque autores como Green são levados a afirmar que o "ponto mais obscuro [da teoria pulsional] é a natureza do vínculo do psiquismo com o corporal" (Green, 1982, p. 20I). Ora, mas isso nos remete novamente à afirmação de Freud em a Concepção das Afasias: "O encadeamento de processos fisiológicos no sistema nervoso provavelmente não se encontra numa relação de causalidade com os processos psíquicos. Os processos fisiológicos não são interrompidos onde começam os processos psíquicos" (Freud, 1983, p. I05).

Ao afirmar que náo existe ruptura entre o fisiológico e o psicológico, Freud propóe que essas instâncias tenham uma relação de interdependência, ou seja, que as alterações fisiológicas do sistema nervoso são representadas no aparelho psíquico concomitantemente à sua ocorrência. Supomos o mesmo para as pulsóes, que ora são elas mesmas conceitos limites e representaçôes dentro do psiquismo, ora necessitam de agentes representantes de pulsôes ou de um conjunto delas. Não há uma descontinuidade entre os processos, uma vez que em última instância, o substrato psíquico é o corpo, ou o próprio sistema nervoso. Já Strachey observara que "pode ser que a contradição seja mais aparente do que real, e que sua solução resida precisamente na ambiguidade do conceito mesmo - em seu caráter de conceito fronteiriço entre o físico e o anímico" (Freud, 2004d, p. IO9).

O conceito de pulsão ocupa assim um lugar central na Metapsicologia freudiana. Mas pode-se dizer que ele se encontra no fulcro da própria Psicanálise como saber dotado de estatuto próprio. É um conceito que se póe sempre com uma dupla referência ao físico e ao anímico: primeiro nas pulsões sexual e de auto-conservação, depois nas pulsões sexual e egóica, e, por fim, nas pulsóes de vida e de morte. Com isso, não é que a pulsão transite entre dois polos, do corpo e da alma, o vital e o simbólico - ela os institui enquanto tais, na medida em que permite tomar essas palavras como se referindo a objetos que não são mais os da medicina ou da fisiologia tradicionais, nem tampouco da metafísica ligada a elas. O corpo e a alma da Psicanálise, a vida e o simbolismo que ela tematiza são domínios novos, como que estruturados e problematizados através da posição do conceito de pulsão. A representação é, em alguma medida, um arranjo de fibras nervosas. 
Mas, quando se diz que ela é também, ao mesmo tempo, imagem abstrata de coisas e de palavras, o sentido da primeira afirmação se altera por completo.

\section{Referências bibliográficas}

Anzieu, D. (1995). Le moi-peau. Paris: Dunod.

Birman, J. (1993). Ensaios de Teoria Psicanalitica. Rio de Janeiro: Jorge Zahar.

Freud, S. (1983) Contribution à la conception des aphasies (189I). Trad. Claude van Reeth. Paris: PUf.

(1986). "Correspondência de 02.04.I896." In: A Correspondência Completa de Sigmund Freud para Wilhem Fliess - 1887-1904. Ed. Jeffrey Moussaieff Masson. Trad. Vera Ribeiro. Rio de Janeiro: Imago.

(2004a). "Proyecto de psicología". In: Publicaciones prepsicoanalíticas y manscritos inéditos en vida de Freud (I886-1899), v. I, Trad. José Luis Etcheverry. Buenos Aires: Amorrortu editores.

(2004b). La interpretación de los sueños (primera parte) (I900), v. IV. Trad. José Luis Etcheverry. Buenos Aires: Amorrortu editores.

(2004c). "Tres ensayos de teoría sexual". In: Fragmento de análisis de un caso de histeria, Tres ensayos de teoría sexual y otras obras (I9OI-I905), v. vir. Trad. José Luis Etcheverry. Buenos Aires: Amorrortu editores.

(2004d). "Pulsiones y destinos de pulsión". In: Contributión a la historia del movimiento psicoanalitico, trabajos sobre metapsicología y otras obras (I9I4-I9I6), v. XIV. Trad. José Luis Etcheverry. Buenos Aires: Amorrortu editores.

(2004e). "Lo Inconciente": In: Contributión a la historia del movimiento psicoanalítico, trabajos sobre metapsicología y otras obras (I9I4-I9I6), v. XIv. Trad. José Luis Etcheverry. Buenos Aires: Amorrortu editores.

Gabbi Jr, O. F. (199i). “Memória e desejo”. In: Filosofia da Psicanálise. São Paulo: Ed. Brasiliense.

Green, A. (1982). O discurso vivo, uma teoria psicanalitica do afeto. Trad. Ruth Joffily Dias. Rio de Janeiro: Francisco Alves.

Greenberg, V. D. (1997). Freud and his aphasia book. New York: Cornell University Press.

Mannoni, O. (1994). Freud, uma biografia ilustrada. Rio de Janeiro: Jorge Zahar Editores.

Monzani, L. R. (2005). "O suplemento e o excesso". In: Fulgencio, L. e Simanke, R. T. (Orgs.), Freud na filosofia brasileira. São Paulo: Escuta.

Rancière, J. (20OI). L’inconscient esthétique. Paris: Galilée.

Torres Filho, R. R. (2006). "O simbólico em Schelling". In: Ensaios de filosofia ilustrada. $2^{\mathrm{a}}$ ediçấo. São Paulo: Iluminuras. 